\title{
Enhanced Phase-Shifted PWM Carrier Disposition for Interleaved Voltage Source Inverters
}

\author{
Gabriel J. Capella, Josep Pou, Senior Member, IEEE, Salvador Ceballos, Georgios Konstantinou, Member, IEEE, \\ Jordi Zaragoza, Member, IEEE, and Vassilios G. Agelidis, Senior Member, IEEE
}

\begin{abstract}
This letter presents a novel implementation of pulsewidth modulation (PWM) that improves the quality of the lineto-line output voltages in interleaved multi-phase voltage source inverters (VSIs). In multi-phase VSIs with $\boldsymbol{n}$ interleaved parallelconnected legs, the best single-phase output voltage is achieved when the carriers are evenly phase shifted. However, switching among non adjacent levels can be observed at regular intervals in the line-to-line voltages, causing bad harmonic performance. With the proposed method, switching in the line-to-line voltages happens exclusively between adjacent levels. The modulator utilizes two sets of $n$ evenly phase-shifted carriers that are dynamically allocated. Because of its generality, the proposed implementation is valid for any number of phases and any number of legs in parallel. A Matlab/Simulink model has been set up for simulation purposes. Selected experimental results obtained from a three-phase VSI made up with two and three legs in parallel per phase are reported, confirming the enhancement attained with the proposed implementation.
\end{abstract}

Index Terms-Voltage-source inverter, legs connected in parallel, interleaving, pulsewidth modulation.

\section{INTRODUCTION}

$\mathbf{V}$ OLTAGE source inverters (VSI) with legs connected in parallel (see Fig. 1) are widely used when high output currents are to be achieved, thus increasing the overall output power [1]-[3]. Inductors are the passive components used to connect several phase legs in parallel [4]-[7]. They not only limit circulating currents among the phase legs but also qualify for averaging the voltage from the legs to form the output voltage. If interleaving is used, the Thevenin equivalent output voltage of a phase with $n$ legs connected in parallel has $n+1$ levels, because of the averaging effect.

Manuscript received May 6, 2014; revised June 13; accepted July 3, 2014. Copyright (92014 IEEE. Personal use of this material is permitted. However, permission to use this material for any other purposes must be obtained from the IEEE by sending a request to pubs-permissions@ieee.org.

This work has been supported by the Ministerio de Economía y Competitividad of Spain under project ENE2012-36871-C02-00.

G.J. Capellá and J. Zaragoza are with the Terrassa Industrial Electronics Group, Technical University of Catalonia, Terrassa, 08222, Catalonia, Spain (e-mail: gabriel.jose.capella@upc.edu, jordi.zaragoza-bertomeu@upc.edu).

J. Pou is with the Australian Energy Research Institute and the School of Electrical Engineering and Telecommunications, The University of New South Wales, Sydney, NSW, 2052, Australia, on leave from the Technical University of Catalonia, Barcelona, 08034, Catalonia, Spain (e-mail: j.pou@ unsw.edu.au, josep.pou@upc.edu).

S. Ceballos is with the Energy Unit, Tecnalia Research and Innovation, Derio, 48160, Basque Country, Spain (e-mail: salvador.ceballos@tecnalia.com).

G. Konstantinou and V. G. Agelidis are with the Australian Energy Research Institute and the School of Electrical Engineering and Telecommunications, The University of New South Wales, Sydney, NSW, 2052, Australia (e-mail: g.konstantinou@unsw.edu.au, vassilios. agelidis@unsw.edu.au).

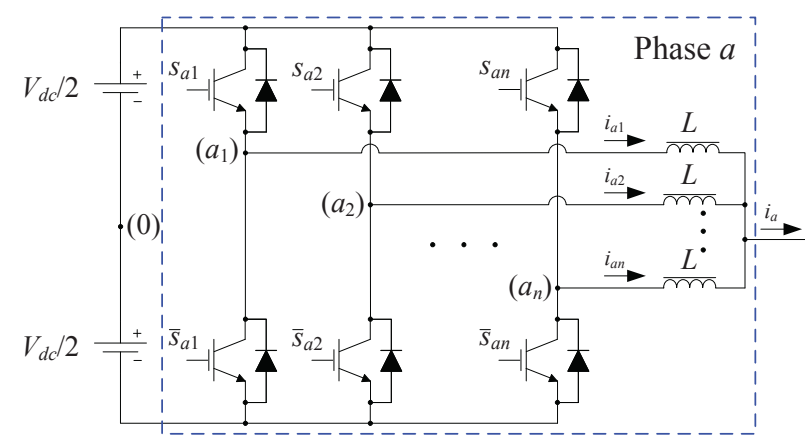

Fig. 1. One phase of a VSI incorporating $n$ legs connected in parallel.

Different methods to set the instantaneous output voltage level can be used, including space vector modulation (SVM) or carrier-based pulse-width modulation (CB-PWM). The effect on their harmonic spectra has been largely investigated [8][12]. In CB-PWM, the use of as many carriers as legs are connected in parallel is the standard procedure if interleaving is to be implemented. In an interleaved phase-shifted PWM (PS-PWM) scheme, all the carriers have the same frequency and amplitude (usually ranging from -1 to +1 per unit) and are evenly phase-shifted within a switching period. Each carrier is associated with a specific leg. In level-shifted PWM (LSPWM) schemes, $n$ triangular carriers with the same frequency and $2 / n$ peak-to-peak value are arranged in contiguous zones to fully occupy the range from -1 to +1 . Depending on the relative phase relationship among the carriers, different PWM strategies are commonly referenced. The most popular one is phase-disposition PWM (PD-PWM) [9].

In multilevel inverters, a PD-PWM scheme provides line-toline voltages where switching happens only between adjacent levels. However, LS-PWM techniques, such as PD-PWM, cannot be applied without modification in converters with legs connected in parallel. If each carrier were associated with one leg, only the leg associated with the carrier in the zone where the reference signal was, would be switching. The remaining $n-1$ legs would be clamped to either the positive or the negative dc-link voltage, depending on the relative position of their reference signal. This process would create dc-voltage components across the inductors and produce extremely large circulating currents.

This paper proposes a new PS-PWM implementation for interleaved multi-phase VSIs where switching in the line-toline voltages happens exclusively between adjacent levels. As a consequence, the proposed modulator improves the quality 
of the line-to-line output voltages when compared to the conventional PS-PWM implementation. For a VSI with $n$ legs in parallel, the modulator utilizes two sets of $n$ evenly phaseshifted carriers that are dynamically allocated. Because of its generality, the proposed implementation can be applied to VSIs with any number of phases and any number of legs connected in parallel.

The rest of the letter is organized as follows. First, the concept of interleaved PS-PWM is reviewed in Section II. Then, the implementation of the proposed modulation scheme is presented in Section III. Simulation and experimental results that illustrate the improvements achieved in terms of total harmonic distortion (THD) and waveform quality in the lineto-line voltages are given in Section IV. Finally, conclusions from this work are presented in Section V.

\section{INTERLEAVED PHASE-SHIFTED PWM}

The interleaving technique is applied to VSIs with legs in parallel to achieve an apparent switching frequency $n$ times higher than the individual switching frequency of each leg [6]. When operating with a CB-PWM this is achieved by using $n$ evenly phase-shifted carriers. Since there are $n$ legs connected in parallel per phase, the Thevenin-equivalent output voltage of the $y$-phase becomes

$$
v_{y}=\frac{1}{n} \sum_{x=1}^{n} v_{y x}
$$

due to the averaging effect of the parallel connection. The equivalent line-to-line voltage is the difference between the equivalent output voltage of two phases.

Fig. 2(a) illustrates the case of a three-phase VSI with three legs in parallel per phase. The phase angles for the three carriers used $\left(v_{c 11}, v_{c 12}\right.$, and $\left.v_{c 13}\right)$ are $0^{\circ}, 120^{\circ}$, and $240^{\circ}$, respectively. The reference signals $\left(v_{\text {ref } a}, v_{\text {ref } b}\right.$, and $\left.v_{\text {refc } c}\right)$ are compared to their respective carrier signal to set the onoff state of the switches. In order to further extend the range of the linear modulation index $\left(m_{a}\right)$ up to 1.15 , the offset voltage

$v_{\text {offset }}=-\frac{\max \left(v_{r e f a}, v_{r e f b}, v_{r e f c}\right)+\min \left(v_{r e f a}, v_{r e f b}, v_{r e f c}\right)}{2}$

is added as a zero sequence component to the three-phase references. The same equivalent output voltages as if centered SVM was used are obtained [13].

Although the use of a set of evenly shifted carriers yields the best attainable single-phase output voltage in terms of THD, that is not the case for line-to-line output voltages [8]. From the equivalent line-to-line voltage in Fig. 2(a), it can be observed that during certain intervals there is switching among three adjacent levels, thus worsening the overall THD and with negative implications in terms of electromagnetic interference on account of bigger voltage steps. The use of a different, but also evenly phase-shifted, set of carriers does not fix that. But if two different sets of carriers are used to modulate two different phases, the periods of time where threelevel switching in the line-to-line voltages is observed, vary. Fig. 2(b) depicts the results obtained for the aforementioned VSI if $v_{r e f a}$ is modulated by means of the first set of carriers,

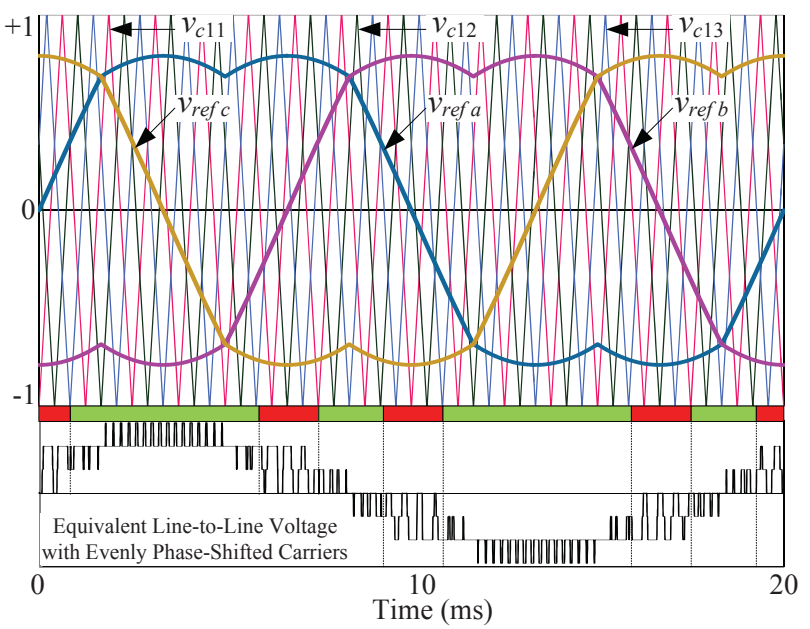

(a)

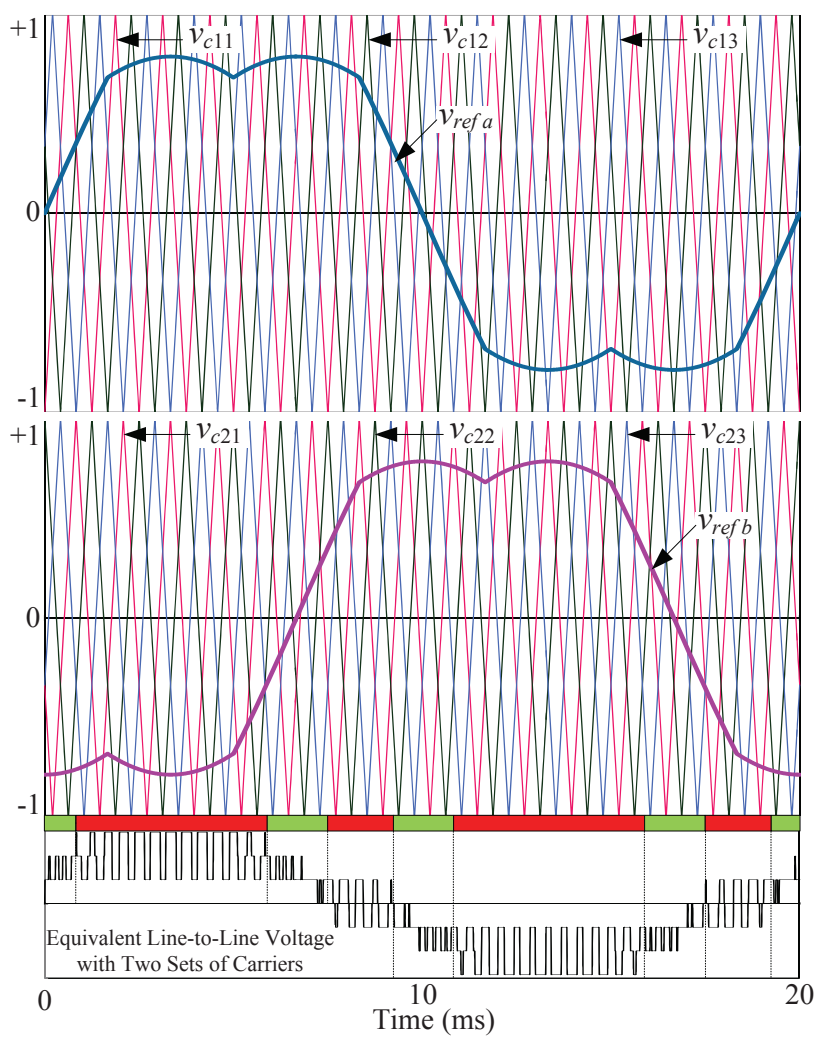

(b)

Fig. 2. Voltage references, set of carriers, and Thevenin-equivalent line-toline output voltage $\left(v_{a b}\right)$ for a three-phase VSI with three legs connected in parallel for $m_{a}=0.8$ and $f_{c}=800 \mathrm{~Hz}$ : (a) one set of carriers and (b) two sets of carriers.

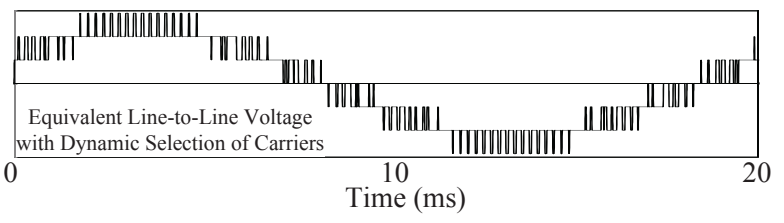

Fig. 3. Line-to-line voltage waveform for a three-phase VSI with three legs in parallel per phase achieved when using a dynamic assignment of carriers.

i.e. $v_{c 11}, v_{c 12}$, and $v_{c 13}$, and $v_{r e f b}$ is modulated by means 


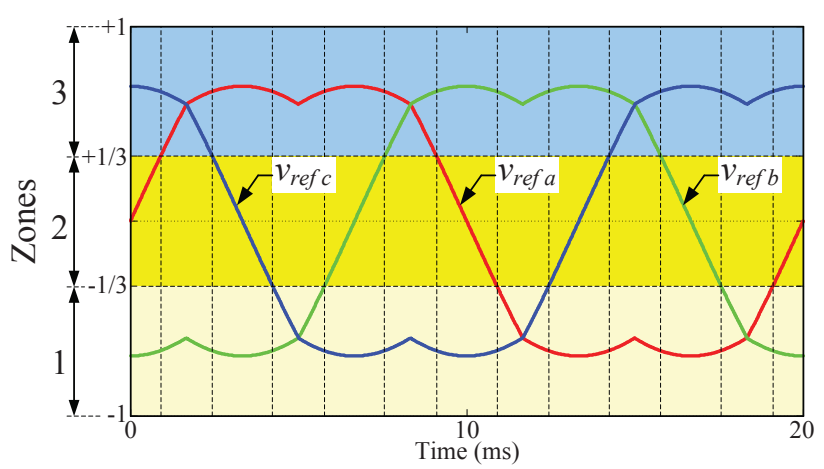

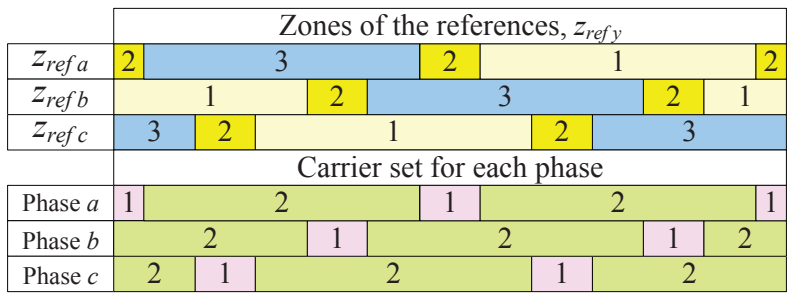

Fig. 4. Single-phase voltage reference zones and carrier set allocation for a three-phase three-paralleled-leg VSI.

of a second set of carriers, i.e. $v_{c 21}, v_{c 22}$, and $v_{c 23}$, whose respective angle phases are $60^{\circ}, 180^{\circ}$, and $300^{\circ}$.

Upon scrutinizing the examples shown in Fig. 2, one can conclude that those intervals of two-level and three-level switching, when using one or another set of carriers, are fully complementary. As a consequence, line-to-line output voltages with switching only happening between adjacent levels are achievable with a dynamic selection of the appropriate set of carriers, as can be seen in Fig. 3. The proposed implementation is described in Section III.

\section{ENhanced Modulator}

The new modulator requires the use of two sets of carriers. For the general case of $n$ legs connected in parallel per phase, carrier Set 1 is made up of $n$ phase-shifted carriers $\left(v_{c 11}, v_{c 12}\right.$, ..., and $v_{c 1 n}$ ) with a relative phase shift of $360^{\circ} / n$. A second set of carriers $\left(v_{c 21}, v_{c 22}, \ldots\right.$, and $\left.v_{c 2 n}\right)$ - Set 2-is also evenly phase shifted, but the whole set is phase-shifted by $360^{\circ} /(2 n)$ with regards to Set 1 . Table I shows the relative phase-shifting among the carriers. The phase shift depends on the number of carriers, i.e. the number of legs in parallel.

The carrier set selection is dynamically assessed depending on the instantaneous value of the modulating reference signals $\left(v_{r e f a}, v_{r e f b}, \ldots\right.$, and $\left.v_{\text {ref } m}\right)$. For that purpose, and considering linear modulation, the carrier/reference signal domain (which ranges from -1 to +1 ) is broken down into $n$ equally sized zones of $2 / n$ peak-to-peak value that are numbered upwards as it is shown in Fig. 4. In order to quantize them, the following expression is used:

$$
z_{\text {refy }}=1+\left\lfloor\frac{1+v_{\text {refy }}}{\frac{2}{n}}\right\rfloor \quad \text { for } \quad y=\{a, b, \ldots, m\}
$$

where $z_{\text {refy }}$ variables can take values from 1 to $n$.

Fig. 5 shows a block diagram of the proposed modulator for $m$ phases and $n$ legs per phase. The modulators for each phase

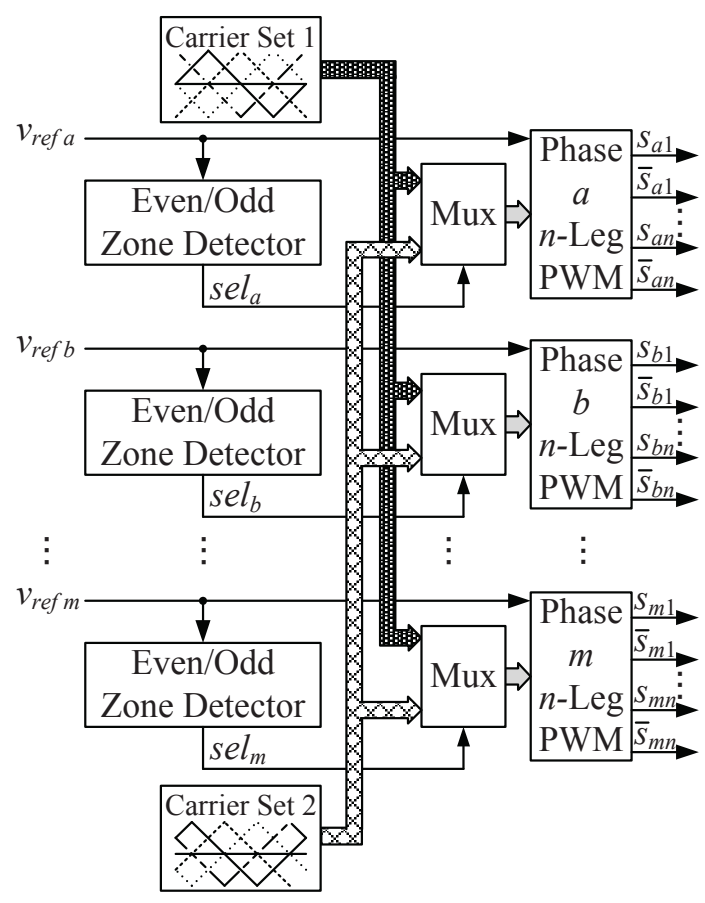

Fig. 5. Generalized $m$-phase $n$-leg modulator diagram.

TABLE I

Phase Shift of the Two Sets of Carriers

\begin{tabular}{c|c|c}
\hline \multirow{2}{*}{$\begin{array}{c}\text { Number of } \\
\text { carriers }\end{array}$} & Carriers' Phase Shift $\left({ }^{\circ}\right)$ \\
\cline { 2 - 3 } & Set 1 & Set 2 \\
\hline 2 & 0,180 & 90,270 \\
3 & $0,120,240$ & $60,180,300$ \\
4 & $0,90,180,270$ & $45,135,225,315$ \\
$n$ & $360\left(0, \frac{1}{n}, \ldots, \frac{n-1}{n}\right)$ & $360\left(\frac{1}{2 n}, \frac{3}{2 n}, \ldots, \frac{2 n-1}{2 n}\right)$ \\
\hline
\end{tabular}

use either Set 1 or Set 2 depending on the position of their reference signals. The Even/Odd Zone Detectors pinpoint the zones where the reference signals are, and generate the $z_{\text {ref } a}$, $z_{\text {ref } b}, \ldots$, and $z_{\text {refm }}$ signals. The Even/Odd Zone Detectors also assess the parity of the $z_{\text {refy }}$ signals and generate the $\mathrm{sel}_{y}$ selection signals according to:

$$
\operatorname{sel}_{y}=\bmod \left[z_{\text {ref }}, 2\right] \text { for } \quad y=\{a, b, \ldots, m\} .
$$

Depending whether a phase reference signal lies within an even or an odd zone, its modulation is carried out by means of one or another set of carriers, respectively. For the example considered in Fig. 4, Set 1 is assigned to even zones and Set 2 to odd zones. Those sel $_{y}$ signals control the multiplexers that route one or another set of carriers to the PWM blocks that, ultimately, set the on-off state of the VSI switches.

\section{Simulation AND ExPERIMENTAL Results}

\section{A. Simulation Results}

The proposed modulator has been simulated on three- and four-phase Matlab-Simulink models with up to five legs in parallel per phase. Fig. 3 depicts the line-to-line voltage waveform for a three-phase three-leg VSI. The THD values for a three-phase inverter, with a switching frequency of $3 \mathrm{kHz}$, and considering the first 2000 harmonics have been computed 


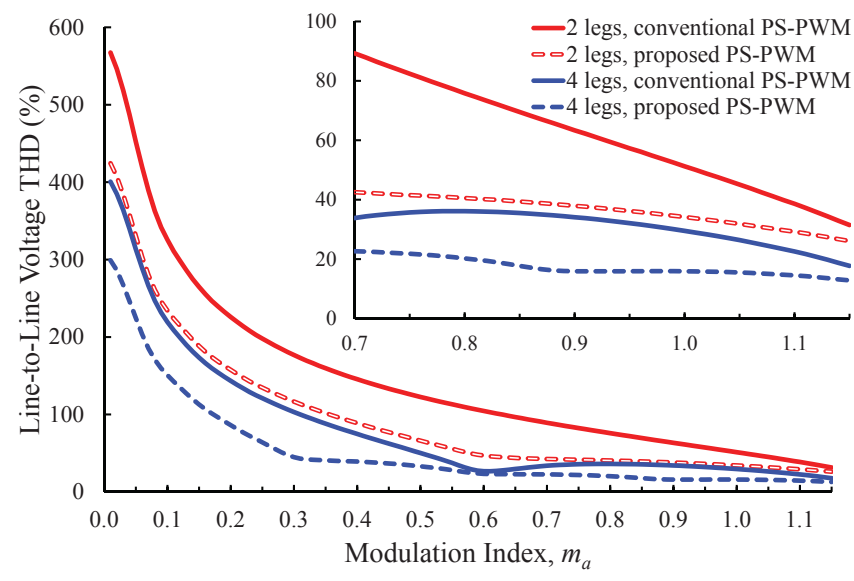

(a)

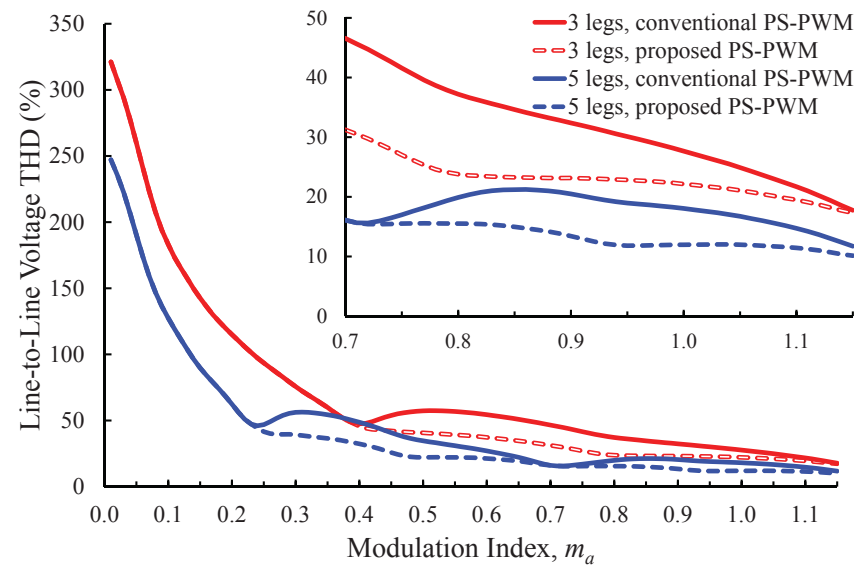

(b)

Fig. 6. Line-to-line THD vs. modulation index for: (a) 2 and 4 legs in parallel, and (b) 3 and 5 legs in parallel.

and plotted in Fig. 6. It can be seen that for an odd number of legs, i.e. an odd number of zones, the improvement in the THD is only achieved if the reference signal exceeds the central zone, e.g. $m_{a}>1 / n$.

\section{B. Experimental Results}

A three-phase modulator has been implemented on a dSpace DS1103 PPC Controller board and tested on a laboratory prototype. There are two three-phase VSIs in the lab, which leaves up to six legs available for different connections. Two different configurations have been studied: (i) a full threephase VSI with two legs in parallel per phase, and (ii) the implementation of phases $a$ and $b$ of a VSI with three legs per phase. Nevertheless, those two phases are modulated as if a full three-phase system had been implemented. The parameters that are common for both configurations are: dc bus voltage $V_{d c}=48 \mathrm{~V}$, carrier frequency $f_{c}=2 \mathrm{kHz}$, inductors $L=6 \mathrm{mH}$, and Wye-connected load resistors $R=10 \Omega$. In order to be able to visualize the Thevenin output voltage, two (or three, depending on the configuration) $10-\mathrm{k} \Omega$ Wye-connected resistors have been connected to the mid point of each leg.

Fig. 7 corresponds to the case of two-legs per phase with $m_{a}=0.8$. It shows the phase voltage $\left(v_{a}\right)$, the line-to-line voltage $\left(v_{a b}\right)$, the phase current $\left(i_{a}\right)$, and the leg currents $\left(i_{a 1}\right.$

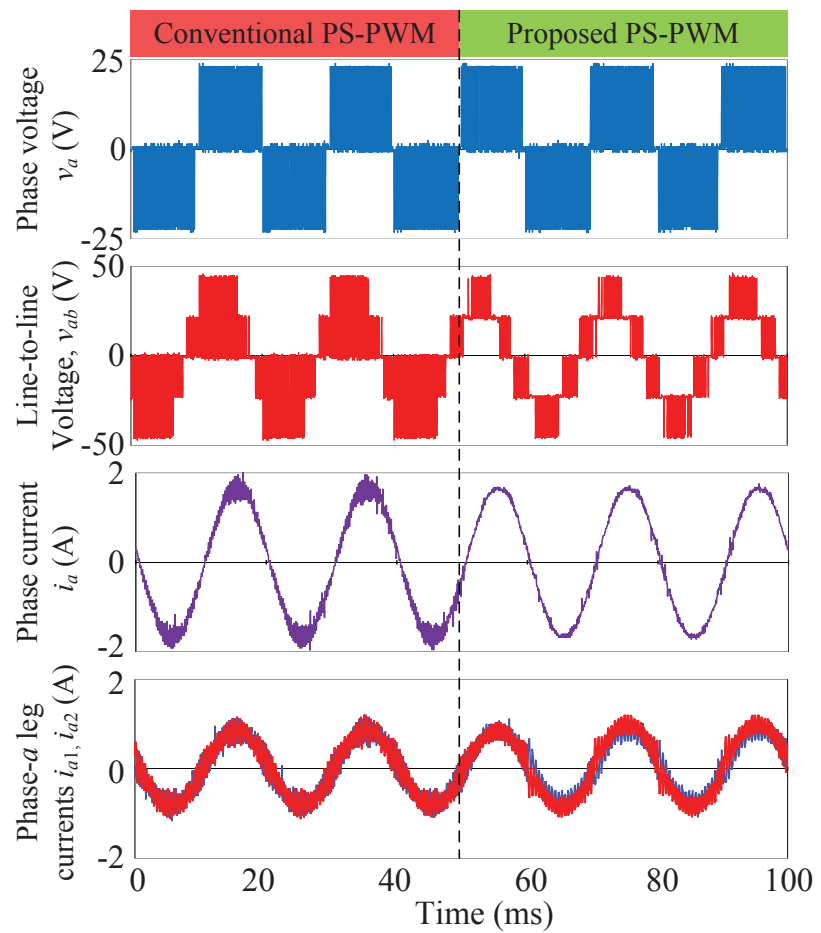

Fig. 7. Experimental results with two legs connected in parallel. Transient from conventional PS-PWM to proposed PS-PWM with a modulation index $m_{a}=0.8$. From top to bottom: phase voltage, line-to-line voltage, phase current, and leg currents.

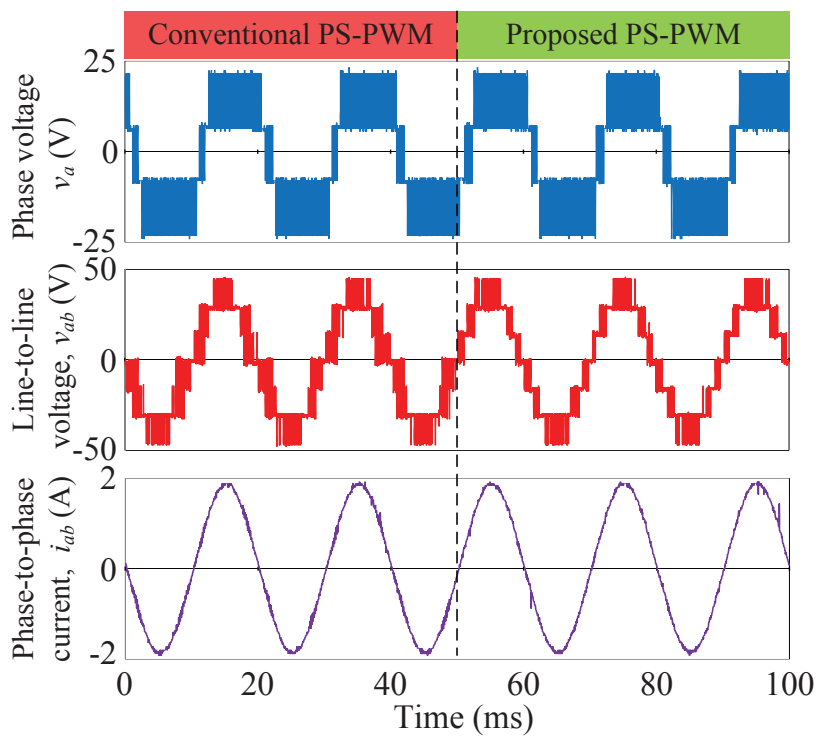

Fig. 8. Experimental results with three legs connected in parallel. Transient from conventional PS-PWM to proposed PS-PWM with a modulation index $m_{a}=1.0$. From top to bottom: phase voltage, line-to-line voltage, and phaseto-phase current.

and $i_{a 2}$ ) for that phase. At the beginning of the figure the modulation is carried out with only one set of carriers, i.e. using conventional PS-PWM. From $t=50 \mathrm{~ms}$ on, the proposed PS-PWM method is used. Although the waveform of the phase voltage is not visually affected, the improvement in the line-toline voltage is significant. There is also a perceptible reduction in the current ripple. It can be seen that the change from 

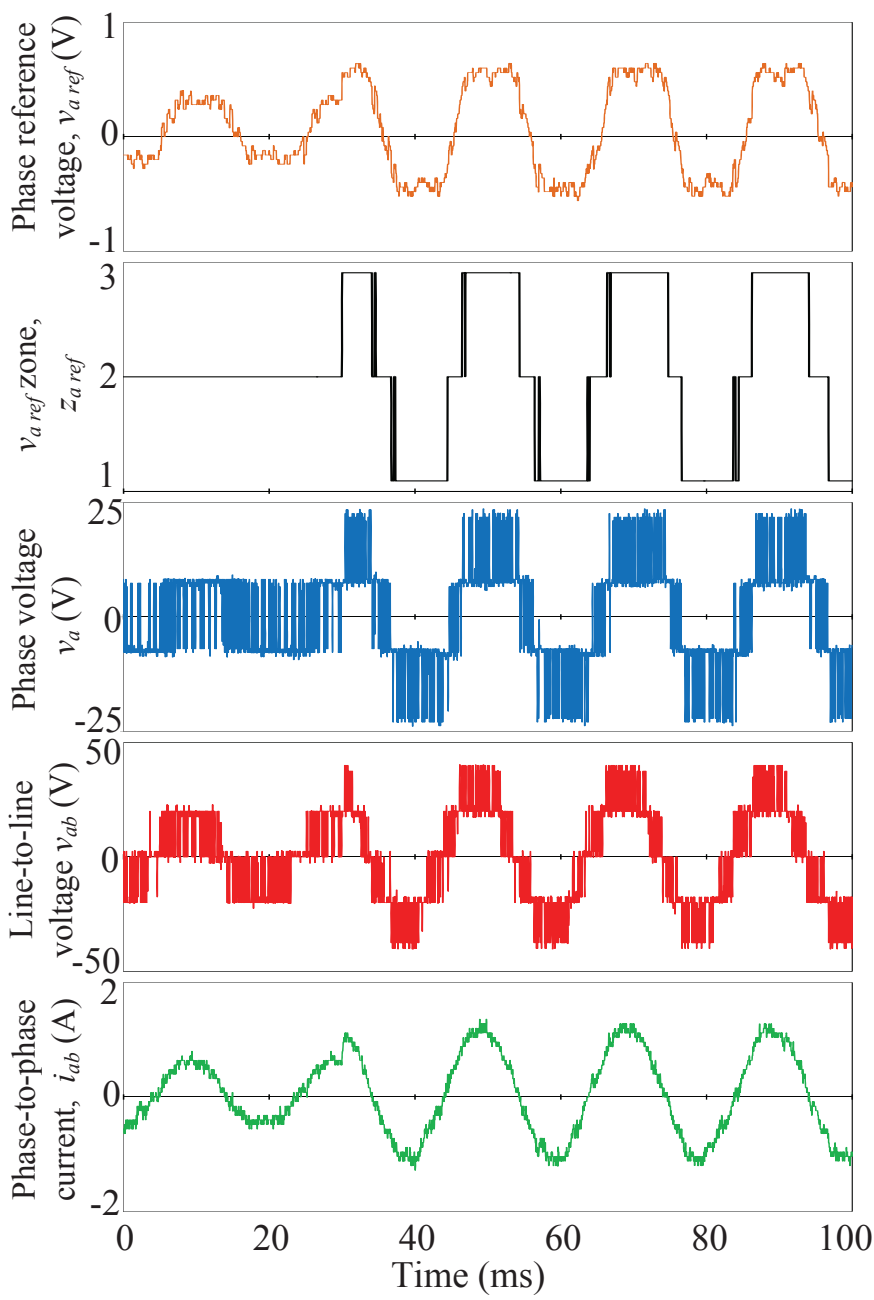

Fig. 9. Experimental results with three legs connected in parallel showing a step in the modulation index $m_{a}$ from 0.3 to 0.6 . The reference signal includes random noise to represent a control action. From top to bottom: phase- $a$ reference voltage, reference zone, phase voltage, line-to-line voltage, and phase-to-phase current

the conventional to the proposed PS-PWM causes a slight imbalance in the leg currents that is not significant.

The experimental results obtained with three legs per phase, can be seen in Figs. 8 and 9. As phase $c$ is not implemented in this configuration, the resistor load between phases $a$ and $b$ is $R=20 \Omega$. Fig. 8 shows the phase voltage $\left(v_{a}\right)$, the lineto-line voltage $\left(v_{a b}\right)$ and the phase-to-phase current $\left(i_{a b}\right)$ for $m_{a}=1.0$. The current ripple reduction and the improvement in the quality of the line-to-line voltage can be noticed here too, although to a lesser extent than in the previous case, with two legs connected in parallel. In order to emulate the behavior of the modulator in a close-loop control system, a randomly shaped signal has been added to the reference signals. Fig. 9 displays such a reference signal for phase- $a\left(v_{r e f a}\right)$, the internal signal generated by the even/odd zone detector $\left(z_{\text {refa }}\right)$, the equivalent phase voltage $\left(v_{a}\right)$, the equivalent line-to-line voltage $\left(v_{a b}\right)$, and the phase-to-phase output current $\left(i_{a b}\right)$. When at first $m_{a}$ is 0.3 , the reference signal is confined to Zone 2 and only one set of carriers is used. At $t=30 \mathrm{~ms}$, there is a step change to $m_{a}=0.6$ and, as all the zones are used, the dynamic selection of the carriers begins. Although the shape of the reference signal causes some additional zone transitions that imply changes in the set of carriers to be used, neither the equivalent phase voltage nor the output current is apparently affected.

\section{CONCLUSION}

This letter has presented a new interleaved PWM implementation for VSIs with legs connected in parallel. With the proposed implementation, the quality of the line-to-line output voltages is improved owing to the fact that switching occurs exclusively between adjacent levels. The modulator makes use of two sets of $n$ evenly phase-shifted carriers that are dynamically allocated. The implementation is presented in a general way so that it can be applied to multi-phase converters with any number of phases and any number of legs in parallel per phase. It is, therefore, appropriate for modular parallel converters. Because of the improvement in terms of line-toline voltages, better THD values are achieved, which can lead to a reduction in the output filtering requirements.

\section{REFERENCES}

[1] X. Zhuang, L. Rui, Z. Hui, X. Dianguo, and C. H. Zhang, "Control of parallel multiple converters for direct-drive permanent-magnet wind power generation systems," IEEE Trans. Power Electron., vol. 27, no. 3, pp. 1259-1270, Mar. 2012.

[2] T. Lazzarin, G. Bauer, and I. Barbi, "A control strategy for parallel operation of single-phase voltage source inverters: analysis, design and experimental results," IEEE Trans. Ind. Electron., vol. 60, no. 6, pp. 2194-2204, Jun. 2013.

[3] M. Borrega, L. Marroyo, R. Gonzalez, J. Balda, and J. L. Agorreta, "Modeling and control of a master-slave PV inverter with n-paralleled inverters and three-phase three-limb inductors," IEEE Trans. Power Electron., vol. 28, no. 6, pp. 2842-2855, Jun. 2013.

[4] E. Laboure, A. Cuniere, T. A. Meynard, F. Forest, and E. Sarraute, "A theoretical approach to intercell transformers, application to interleaved converters," IEEE Trans. Power Electron., vol. 23, no. 1, pp. 464-474, Jan. 2008

[5] G. Zhu, B. McDonald, and K. Wang, "Modeling and analysis of coupled inductors in power converters," IEEE Trans. Power Electron., vol. 26, no. 5, pp. 1355-1363, May 2011.

[6] J. Pou, J. Zaragoza, G. Capella, I. Gabiola, S. Ceballos, and E. Robles, "Current balancing strategy for interleaved voltage source inverters," EPE Journal, vol. 21, no. 1, pp. 29-34, Jun. 2011.

[7] Z. Di, W. Fei, R. Burgos, and D. Boroyevich, "Total flux minimization control for integrated inter-phase inductors in paralleled, interleaved three-phase two-level voltage-source converters with discontinuous space-vector modulation," IEEE Trans. Power Electron., vol. 27, no. 4, pp. 1679-1688, Apr. 2012.

[8] D. G. Holmes and B. P. McGrath, "Opportunities for harmonic cancellation with carrier-based PWM for a two-level and multilevel cascaded inverters," IEEE Trans. Ind. Appl., vol. 37, no. 2, pp. 574-582, Mar./Apr. 2001.

[9] B. P. McGrath and D. G. Holmes, "Multicarrier PWM strategies for multilevel inverters," IEEE Trans. Ind. Electron., vol. 49, no. 4, pp. 858-867, Aug. 2002.

[10] R. Naderi and A. Rahmati, "Phase-shifted carrier PWM technique for general cascaded inverters," IEEE Trans. Power Electron., vol. 23, no. 3, pp. 1257-1269, May 2008.

[11] D. J. Kostic, Z. Z. Avramovic, and N. T. Ciric, "A new approach to theoretical analysis of harmonic content of PWM waveforms of single- and multiple-frequency modulators," IEEE Trans. Power Electron., vol. 28, no. 10, pp. 4557-4567, Oct. 2013.

[12] B. Li, R. Yang, D. Xu, G. Wang, W. Wang, and D. Xu, "Analysis of the phase-shifted carrier modulation for modular multilevel converters," IEEE Trans. Power Electron., DOI 10.1109/TPEL.2014.2299802.

[13] J. Pou, J. Zaragoza, S. Ceballos, M. Saeedifard, and D. Boroyevich, "A carrier-based PWM strategy with zero-sequence voltage injection for a three-level neutral-point-clamped converter," IEEE Trans. Power Electron., vol. 27, no. 2, pp. 642-651, Feb. 2012. 